\title{
Mathematical Probabilistic Thinking Process Stages in Problems Solving Probability
}

\author{
Abd Taram, Y. L. Sukestiyarno, Rochmad, Iwan Junaedi \\ Postgraduate Program of Universitas Negeri Semarang, Jl. Kelud Utara III, Semarang 50237, Indonesia \\ e-mail: abdul.taram@pmat.uad.ac.id
}

\begin{abstract}
Probabilistic thinking is one type of thinking skills which belongs to the Higher Order Thinking Skills (HOTS). Students need to have the probabilistic thinking ability to face the life which is full of uncertainty. The purpose of this research is to formulate the stages of mathematical probabilistic thinking processes in solving probability problems. It was a descriptive qualitative research involving eight students of the $9^{\text {th }}$ grade of SMP Muhammadiyah 3 Mlati Sleman Yogyakarta as the subjects. We administered a probabilistic thinking test and then observed and interviewed them to get the data. The data were then analyzed using triangulation method. This study resulted the five stages of mathematical probabilistic thinking process. They are: (1) understanding the problem of uncertainty that needs to be solved; (2) identifying all possibilities that will occur from a problem; (3) grouping the results of the identified event; (4) determining the probability of the occurred events; and (5) verifying the results.
\end{abstract}

Keywords: higher order thinking skills, probabilistic thinking stages, problem-solving

How to Cite: Taram, A., Sukestiyarno, Y. L., Rochmad, \& Junaedi, I. (2021). Mathematical Probabilistic Thinking Stages in Problem Solving. International Journal on Emerging Mathematics Education, 5(1), 1-10. http://dx.doi.org/10.12928/ijeme.v5i1.20005

\section{INTRODUCTION}

Probabilistic thinking is one type of thinking skills which belongs to the Higher Order Thinking Skills (HOTS). It is in line with Piaget's classification in the characterization of cognitive development that logic and probability are positioned at the formal stage of operation at the age of more than 11 years old, characterized by abstract thinking, hypothesis, deductive, inductive, logical, and probability (Aseeri, 2020). Students need to develop HOTS as it is one of the features and demands of learning in the 21st century.

Research related to probabilistic thinking have been started in the 1990s. A decade later, it became a concern among researchers. This period is called the contemporary research period. After 2010, the period continued to the assimilation period (Chernoff \& Sriraman, 2014). Research on the theme of probabilistic thinking in the early period can be found. For instance, Jones et al $(1997,1999)$ suggested four levels of probabilistic thinking, i.e. subjective, transitional, informal quantitative, and numerical. Further, Polaki (2002) developed the Jones' probabilistic thinking level in more detail for several subjects or materials in probability theory.

During the second period, we could also find a research work by Sujadi (2008). Sujadi developed the Jones' level, too, and adding a level of probabilistic thinking for junior high school students who have not been given probability material previosuly. The findings concluded that junior high school students who have not formally learned about probability have five levels in probabilistic thinking. Manipulation of concrete objects as well as computer animation can help students improve their schemes at level0 "pre subjective probabilistic thinking" related to understanding possible outcomes, as 
well as reducing the influence of irrelevant aspects, although ultimately students were still unable to identify the members of sample space from one-level experiments.

In the assimilation period, Borovcnik (2016) offered the four stages of probabilistic thinking, namely: (1) probability as index of surprise, (2) feedback from probabilistic situations is indirect, (3) causal alternative to randomness, and (4) nonprobabilistic criteria for decisions. Nacarato \& Grando (2014) offered that probabilistic thinking has also four stages, namely: (1) classical concept, (2) frequency or empirical concept, (3) subjectivist concept, and (4) axiomatic or formal concept. Jan \& Amit (2009) built the probabilistic reasoning by offering four categories, namely: (1) types of strategy, (2) representation, (3) use of probabilistic language, and (4) nature of cognitive obstacle.

Furthermore, the philosophical review of probability theory resulted in a thinking trajectory of the students towards problems of uncertainty. The stages are: (1) facing uncertainty related problems, (2) determining all possible outcomes in a problem which have the same probability, (3) identifying some events among all possible outcomes and provides the desired choice, (4) calculating the probability of the identified event, (5) defining the relationship of all results by a set of numbers, (6) determining the value of the relation based on the preset definition, (7) visualizing the value of the relation geometrically, (8) predicting the average or the expectation value of the defined relationship, and (9) determining the distance between the defined relation values.

The discussion related to this type of thinking is not separated by the stages of the problem-solving process offered by Polya (1971). The stages are: (1) understanding the problems, (2) devising a plan, (3) carrying out the plan, and (4) looking back to the solution. On the other hand, Krulick \& Rudnick (1996) and Satchakett \& Art-in (2014) suggested five stages of the process: (1) reading and thinking, (2) analyzing and planning, (3) organizing strategy, (4) getting the answer, and (5) confirming the answer.

The other higher order thinking skills also have their stages. Perkins \& Murphy (2006) suggested that critical thinking has four stages, i.e. clarification, assessment, collection, and strategy. Facione \& Facione (2013) stated that there are six aspects of critical thinking ability, i.e. interpretation, analysis, conclusion, evaluation, explanation, and self-arrangement. Stacey, Burton \& Mason (1982) offered four stages of mathematical thinking, i.e. specializing, conjecturing, generalizing, and convincing. Mason, Burton, \& Stacey (2010) suggested that there were three phases of mathematical thinking, i.e. entry, attack, and review. Critical thinking stages are also suggested by Watson (1980), Perkins \& Murphy (2006), and Facione \& Facione (2013). There are five stages: knowing assumptions, conducting inferences, deductions, interpretations, and evaluating arguments. Finally, creative thinking as stated by Wallas has four stages: preparation, incubation, illumination, and verification (Sadler-Smith, 2015).

Regarding the probabilistic thinking skills, we found that the previous suggested stages have not fully accommodate the Indonesian students' level of probabilistic thinking, especially dealing with problems of probability. We tried to formulate an updated level of probabilistic thinking by combining stages in the problem-solving process, stages of several types of thinking, probabilistic thinking level indicators, and characteristics of probabilistic thinking which allows the probabilistic thinking processes to be formulated in solving probability problems.

\section{RESEARCH METHOD}

This research is a descriptive qualitative research. As told by Creswell (2014), we tried to explore the phenomenon of probabilistic thinking skills in junior high school

IJEME, Vol. 5, No. 1, March 2021, 13-22. 
students and gained a deeper understanding about it. We also tried to seek substantive theories about the probabilistic thinking stages as suggested by Moleong (2015).

We involved eight students from the ninth grade of SMP Muhammadiyah 3 Mlati Sleman Yogyakarta as the research subjects. We selected the subjects purposively, based on the fulfilling of the level categories and also their availability to be interviewed. Therefore, we also considered the teacher's opinion when selecting the subjects.

First, we administered a probabilistic thinking test to 22 students. We observed the results and referred to the hypothetical stages we derived from various stages offered by experts. Then, we selected eight subjects and interviewed them to confirm the data. The data were then analyzed using triangulation method.

\section{RESULTS AND DISCUSSION Proposed Stages of Probabilistic Thinking}

Based on the previous theories of the probabilistic thinking stages, we tried to consider the stages in the problem-solving process, types of thinking, probabilistic thinking level indicators, and characteristics of probabilistic thinking. Therefore, we proposed the updated levels of probabilistic thinking as follows.

1. Understanding the probability problems that need to be solved. Students look at the problems of probability, identify what is given and what is asked in the problem.

2. Identifying all possibilities that will occur from a problem (sample space).

3. Grouping the results of the identified event.

4. Determining the probability of the occurred events.

5. Verifying the results (evaluation).

Probabilistic thinking can certainly be applied in response to a life filled with uncertainty, so that one can make decisions from several alternatives, which are highly likely, or the odds are greater than others, of a problem faced based on certain considerations.

\section{Probability Test Results}

We administered the pretest and posttest of probability problem-solving to 22 students of the ninth grade of SMP Muhammadiyah 3 Mlati. The test was used to categorize the probabilistic thinking levels of the students. The pretest and posttest results are presented in Figure 1.

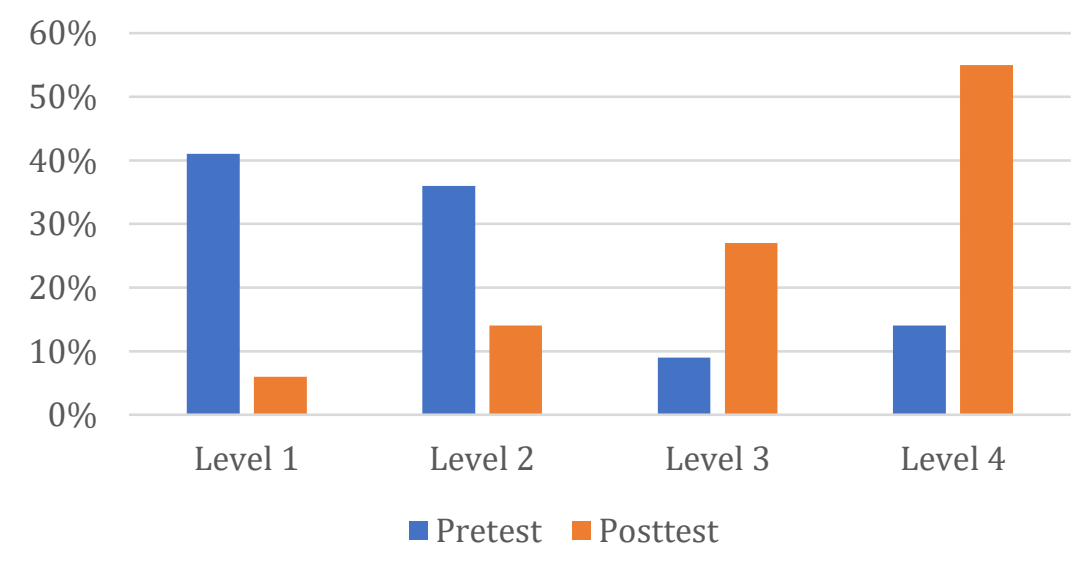

Figure 1. Percentage of students' probabilistic level before and after learning 
Figure 1 shows that most of students have Level 1 probabilistic thinking at the pretest result. Meanwhile, at the posttest results, most of students could perform Level 4 of the probabilistic thinking.

The students' posttest results after participating in a cooperative learning model of NHT-modified type increased by 13 students (59.09\%), 7 students $(31.82 \%)$ remained at the same level, while 2 students (9.9\%) decreased the level. The percentage increase in probabilistic thinking levels is much greater than others, this indicates that cooperative-modification learning, and curiosity contributes to increasing or improving students' ability to solve probability problems. We triangulated by comparing and reexamining the degree of confidence in the data of the study results related to the solution of probability problems. We interviewed eight subjects representing four levels of probabilistic thinking, each level was taken by 2 subjects, as presented in Table 1.

Table 1. Research subjects

\begin{tabular}{cccc}
\hline No & Subjects' Initial & Level & Code \\
\hline 1. & IY & Level 1 & BP1-1 \\
2. & RJN & Level 1 & BP1-2 \\
3. & GES & Level 2 & BP2-3 \\
4. & AG & Level 2 & BP2-4 \\
5. & TWS & Level 3 & BP3-5 \\
6. & DR & Level 3 & BP3-6 \\
7. & AIA & Level 4 & BP4-7 \\
8. & AL & Level 4 & BP4-8 \\
\hline
\end{tabular}

Research subjects were selected based on teacher considerations and researchers' observations to represent each level of probability thinking. Each research subject is coded, this is to facilitate discussion. For example, the code BP1-1 means it is the 1 st subject who has probabilistic thinking level 1. BP2-4 means the 4 th subject who has probabilistic thinking level 2 .

Furthermore, each research subject was analyzed with detailed triangulation analysis of the results of probability problem solving tests, interview results, which will produce stages of mathematical probabilistic thinking process by comparing subjects with level-1 and level-4 on probabilistic thinking.

\section{Stages of Mathematical Probabilistic Thinking Process}

Five stages were found in this study as follows.

\section{Stage 1}

We observed the results of the subjects' answer of BP1-1 and BP1-2. The interview revealed that they expressed confusion to understand the problem. The interview transcript is as follows.
$R \quad$ :Is it all the answer?
BP1012 : No, there's more but I'm a no understand.
$R \quad$ : How did you answer the next question?
BP2007 : Combined from red and blue marbles.
$R \quad$ : How did you do that?
BP2008 :Yes, I combined two reds and two blues.

IJEME, Vol. 5, No. 1, March 2021, 13-22. 
Regarding the answer of subject BP4-7 and BP4-8, both have a good understanding of the problems. The results of the interview found no expression that shows no mastery of the problem, all convincing interview answers such as the following transcript.

$R \quad$ : Now, how could you answer like this? (See Figure 2)

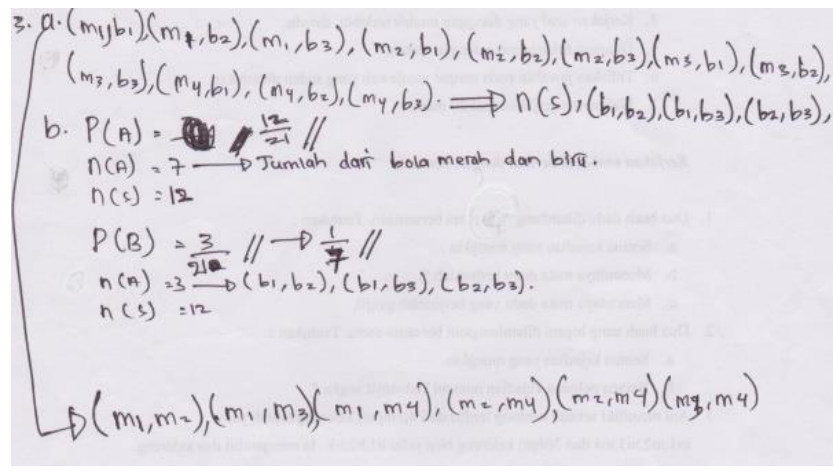

Figure 2. Work of Subject BP4-7

BP7008 : Take out first red and blue marbles, then connected between marbles.

Comparing the answers between subjects at level- 1 and level-4, it appears that the level of problem mastery, has a fundamental role to the probabilistic thought process in solving probability problems. That is why understanding the problem is the first stage in the probabilistic thinking process.

\section{Stage 2}

We observed the results of the subjects' answer of BP1-1 and BP1-2. The interview revealed that they could not identify all members of the sample space. The interview transcript is as follows.

$R \quad$ : How do you write down all possible events?

BP1010 : Spelled out from the same red ball and blue ball.

$R \quad$ : How did you do that?

BP1011 : Combined between the red ball and the blue ball and so on. (See Figure 3)

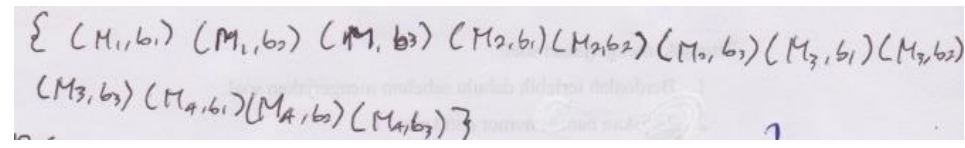

$R \quad$ : Is that all?

Figure 3. Work of Subject BP1-1

BP1012 : No, there's more but I don't know.

$R \quad:$ How can you name all the possible events like that?

BP3008 : This is spelled one-by-one, then combined the marbles. (See Figure 4).

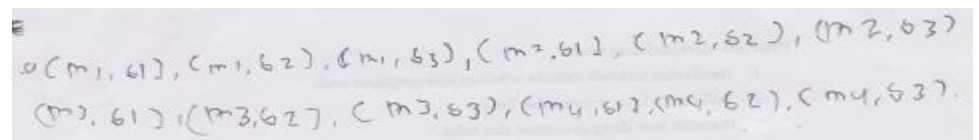

Figure 4. Work of Subject BP1-2 
Note that with the answer to the subject BP4-7 and BP4-8, both of which have the ability to identify all possibilities that occur. The results of the interview show the ability to identify all possible outcome that occur from a problem, this is demonstrated by writing down all members of the sample space in full accompanied by the strategy indicated by creating a pattern. All interview answers from both are convincing such as follows.

$R \quad$ : How to find the probability?

BP8008 : Spelled out two-two between red and blue marbles.

$R \quad$ : How did you do that?

BP8009 : Marbles $m 1$ with b1, $m 1$ with b2, and so on. (See Figure 5)

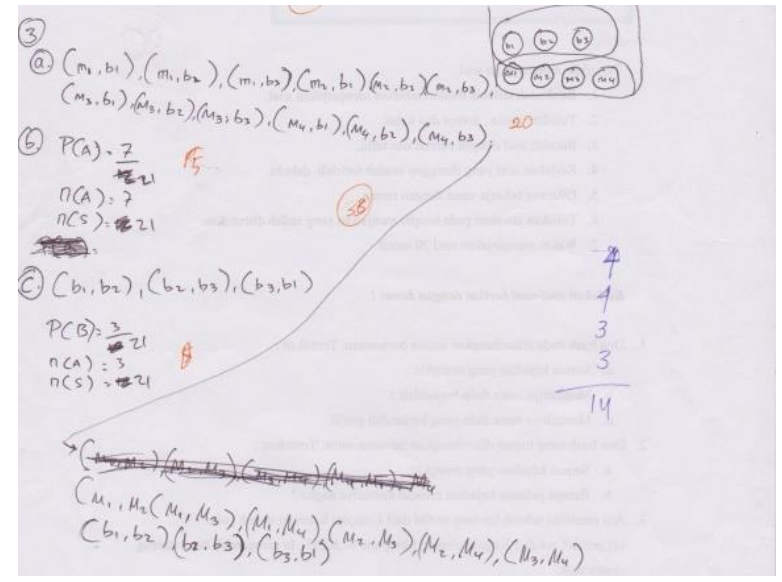

Figure 5. Work of Subject BP4-8

$R \quad$ : How many members of the sample space are there?

BP8010 : Its members are 21.

Comparing the answers between subjects at level-1 and level-4, it appears that the level of ability to identify all possibilities of a problem, has an important role to play in the probabilistic thinking process in solving probability problems. That is why identifying all the possibilities that will occur from a problem is stage 2 in the probabilistic thinking process.

\section{Stage 3}

We observed the results of the subjects' answer of BP1-1 and BP1-2. It was related to the grouping of the results of the identification stage. The interview revealed that they both showed an inability to group the results of the identification, both did not write down a requested event and did not write down the membership of the event. The interview transcript is as follows.

$R \quad$ : Then for the question $b$ and c how can you answer like this? (See Figure 6)

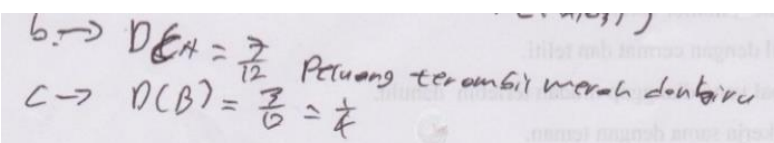

Figure 6. Work of Subject BP1-2

IJEME, Vol. 5, No. 1, March 2021, 13-22. 


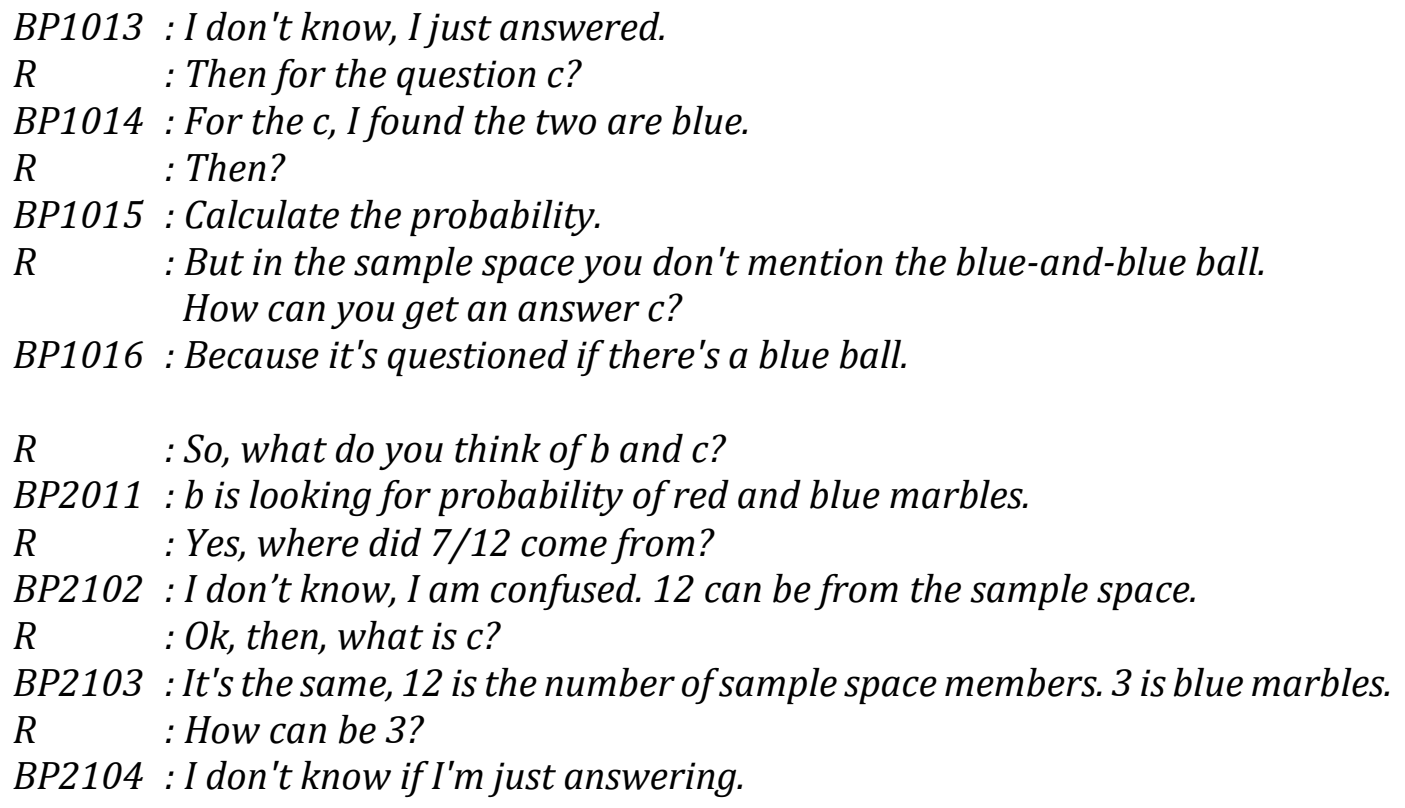

Note that with the answer of the subject BP4-7 and BP4-8, both have the ability of grouping the results of the identification. The results of the interview to both subjects show the ability to group the identification results. This is indicated by writing the event and all members of an event in full accompanied by the strategy indicated by creating a pattern. All the answers of the interview are both convincing as follows.

$R \quad:$ For question $b$, how did you find probability of 1 red and 1 blue?

BP7010: I see first in the sample space that there are 1 red and 1 blue, such as $m 1$ with b1, $m 1$ with b2, and so on. And I'm looking for 12, and then there's 21 total sample space members. So, 12/21 reduced to 4/7.

$R \quad$ :Then, how about question $c$ ?

BP7011 : Same with b, but I looked at two blue marbles. I look at two blues. It was only $3,(b 1, b 2),(b 1, b 3)$, and $(b 2, b 3)$. Then, $3 / 21$ is reduced to $1 / 7$.

$R \quad$ : For question $b$, how to solve it? (See Figure 7)

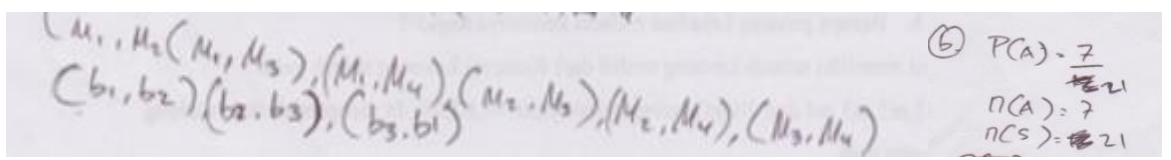

Figure 7. Work of Subject 7

BP8011 : Using the probability formula $P(A)=(n(A)) /(n(S))$, $n(A)$ is $7, n(S)$ is 21.

$R \quad$ :How do you get them?

BP8012 : 7 is the number of red and blue marbles, 21 is all events occured.

Comparing the answers between subjects at level-1 and level-4, it appears that the level of the subject's ability to group from the results of identification, has an important role to play in the probabilistic thought process in solving probability problems. That is why grouping from the results of identification is stage 3 in the probabilistic thinking. 


\section{Stage 4}

We observed the results of the subjects' answer of BP1-1 and BP1-2. It was related to the determining the probability of the occurred events stage. The interview revealed that they both showed an inability to determine the magnitude of the possibility of occurring from several groups, both writing down the probability of a requested event but wrongly the result, this was because the previous stage was wrong. The interview transcript is the same presented in Stage 3.

Menawhile, towards the answer of subject BP4-7 and subject BP4-8, both have the ability to determine the magnitude of the probability of occurrence of multiple groups. It is indicated by writing the event and many members of an event and writing the probability formula of an event, all the answers to the interview are both convincing, as also presented in Stage 3.

Comparing the answers between subjects at level-1 and level-4, it appears that the level of the subject's ability to determine the numerical value was correct. This ability has an important role to play in the probabilistic thinking process in solving probability problems. That is why determining the magnitude of the possibility occurs from multiple groups is stage 4 in the probabilistic thinking process.

\section{Stage 5}

We still focus on the same interview transcript in Stage 3 to confirm the stage of verifying the results. Subjects BP1-1 and BP1-2 both showed an inability to verify the results. Both wrote down the probability of the requested event but arrived at the wrong result because both did not verify their answer.

Meanwhile, Subject BP4-7 and subject BP4-8 both have the ability to verify the results. It is indicated by writing the event and many members of an event correctly and writing the probability formula of an event correctly as well, all the answers to the interview are both convincing.

Comparing the answers between subjects at level-1 and level-4, it appears that the level of the subject's ability to determine the probability correctly. This ability has an important role to play in the probabilistic thinking process in solving probability problems. That is why verifying the results is stage 5 in the process.

\section{Discussion}

This section will discuss and formulate the stages of the mathematical probabilistic thinking process in solving the problem of probability. As the basis of its update is the combination of stages in the problem-solving process, stages of the type of thinking, indicators on the leveling of probabilistic thinking, and characteristics of probabilistic thinking based on classical theory. This research proposes five stages of mathematical probabilistic thinking process in solving the probability problems.

Stage 1: Understanding the probability problems that need to be solved. This first stage is in line with the stage in Polya's (1971) problem solving of understanding the problem. It is also in line with; the stage formulated by Krulick \& Rudnick (1996) and Satchakett \& Art-in (2014) of reading and thinking. This first stage is also in accordance with the stage of creative thinking as stated by Wallas in the preparation stage (SadlerSmith, 2015). At the mathematical thinking stage by Stacey, Burton \& Mason (1982), this stage is in line with the specializing stage. This first stage has always been related to the probabilistic leveling of thinking by Jones et al $(1997,1999)$ and Polaki $(2002)$.

Stage 2: Identifying all possibilities that will occur from a problem. This stage is the characteristic specification of the mathematical probabilistic thinking process, 
related to all possibilities and alternatives that may occur in limited, or infinite scopes. This stage corresponds to mathematical thinking as stated by Mason, Burton, \& Stacey (2010) in the first stage of entry, as well as Stacey, Burton \& Mason (1982) in the stage of conjecturing. Regarding the creative thinking by Wallas, it is in accordance with the second stage of incubation (Sadler-Smith, 2015). Moreover, it is also in line with the first stage of the classical concept phase of Nacarato \& Grando (2014). This stage has always been related to the leveling of probabilistic thinking by Jones et al $(1997,1999)$ and Polaki (2002).

Stage 3: Grouping the results of the identified event. This stage is the characteristic specificity of the mathematical probabilistic thinking process, related to the identification and grouping of the second step. This third stage corresponds to mathematical thinking as stated by Mason, Burton, \& Stacey (2010) in the first stage of entry, as well as Stacey, Burton \& Mason (1982) in the second stage conjecturing. While in probabilistic thinking by Nacarato \& Grando (2014), it is in the first phase of the classical concept phase. This third stage has always been related to the probabilistic leveling of thinking put forward by Jones et al $(1997,1999)$ and Polaki $(2002)$.

Stage 4: Determining the probability of the occurred events. This fourth stage corresponds to the mathematical thinking suggested by Mason, Burton, \& Stacey (2010) in the second stage of attack, as well as Stacey, Burton \& Mason (1982) in the second stage of conjecturing, Krulick \& Rudnick (1996), and Satchakett \& Art-in (2014) in the second stage of analyzing and planning. Regarding the Nacarato \& Grando (2014), it is in the first phase of the classical concept phase. This fourth stage is always related to the leveling of probabilistic thinking put forward by Jones et al $(1997,1999)$ and Polaki (2002).

Stage 5: Verifying the results (evaluation). This fifth stage corresponds to the stage in Polya's problem solving (1971) relevant to the fourth stage of look back. While at the stage formulated by Krulick \& Rudnick (1996) and Satchakett \& Art-in (2014), it also corresponded to the fifth stage of confirmation of the answer. This fifth stage is also in accordance with the creative thinking stage as stated by Wallas in accordance with the fourth stage of verification (Sadler-Smith, 2015). At the mathematical thinking stage offered by Stacey, Burton \& Mason (1982), it is in accordance with the third stage of review. This fifth stage is always related to the probabilistic leveling of thinking by Jones et al $(1997,1999)$ and Polaki $(2002)$.

The stages in the probabilistic thought process can certainly be applied in response to a life filled with uncertainty, so that one can make the decision to choose from several alternatives, which is highly likely, or the odds are greater than others, of a problem faced based on certain considerations.

\section{CONCLUSION}

The stages of the mathematical probabilistic thinking process in solving the problem of probability are as follows. First, understanding the probability problems that need to be solved. Students look at the problems of probability, identify what is given and what is asked in the problem. Second, identifying all possibilities that will occur from a problem (sample space). Third, grouping the results of the identified event. Forth, determining the probability of the occurred events. At last, verifying the results.

\section{REFERENCES}

Aseeri, M. M. Y. (2020). Abstract thinking of practicum students at Najran University in light of Piaget's theory and its relation to their academic level. Journal of 
Curriculum and Teaching, 9(1), 63-72.

Borovcnik, M. (2016). Probabilistic thinking and probability literacy in the context of risk. Educação Matemática Pesquisa: Revista do Programa de Estudos PósGraduados em Educação Matemática, 18(3).

Chernoff, E. J., \& Sriraman, B. (2014). Probabilistic thinking: presenting plural perspectives. New York: Springer.

Creswell, J. W. (2014). Research Design: Qualitative, Quantitative, and Mixed Method Approaches. SAGE Publishing.

Facione, P. A., \& Facione, N. C. (2013). Critical thinking for life: Valuing, measuring, and training critical thinking in all its forms. Inquiry: Critical Thinking Across the Disciplines, 28(1), 5-25.

Jan, I., \& Amit, M. (2009). A four phase model for predicting the probabilistic situation of compound events. Beersheba: Ben Gurion University.

Jones, G. A., Langrall, C. W., Thornton, C. A., \& Mogill, A. T. (1997). A framework for assessing and nurturing young children's thinking in probability. Educational Studies in Mathematics, 32(2), 101-125.

Jones, G. A., Langrall, C. W., Thornton, C. A., \& Mogill, A. T. (1999). Students' probabilistic thinking in instruction. Journal for Research in Mathematics Education, 487-519.

Krulik, S., \& Rudnick, J. A. (1996). The new sourcebook for teaching reasoning and problem solving in junior and senior high school. Allyn \& Bacon.

Mason, J., Burton, L., \& Stacey, K. (2010). Thinking mathematically. Pearson Education.

Moleong, L. J. (2015). Metodologi Penelitian Kualitatif. Bandung: Remaja Rosdakarya.

Nacarato, A. M., \& Grando, R. C. (2014). The role of language in building probabilistic thinking. Statistics Education Research Journal, 13(2), 93-103.

Perkins, C., \& Murphy, E. (2006). Identifying and measuring individual engagement in critical thinking in online discussions: An exploratory case study. Journal of Educational Technology \& Society, 9(1), 298-307.

Polaki, M. V. (2002). Assessing and tracing the development of Basotho elementary students' growth in probabilistic thinking. In Proceedings of the Sixth International Conference on Teaching Statistics (ICOTS 6). Lesotho: National University of Lesotho.

Polya, G. (1971). How to Solve It: A New Aspect of Mathematics Method. New Jersey: Princeton University Press.

Sadler-Smith, E. (2015). Wallas' four-stage model of the creative process: More than meets the eye? Creativity Research Journal, 27(4), 342-352.

Satchakett, N., \& Art-in, S. (2014). Development of Heuristics Problem Solving, and learning achievement of grade 9 students by using learning management focusing on Heuristics Approach in Thailand. Procedia-Social and Behavioral Sciences, 116, 1011-1015.

Stacey, K., Burton, L., \& Mason, J. (1982). Thinking mathematically. Addison-Wesley.

Sujadi, I. (2008). Rekonstruksi Tingkat-Tingkat Berpikir Probabilistik Siswa Sekolah Menengah Pertama. In Proceeding Seminar Matematika dan Pendidikan Matematika. FKIP UNS.

Watson, G. (1980). Watson-Glaser critical thinking appraisal. San Antonio, TX: Psychological Corporation. 